\title{
Sound Symbolism in Shakespeare's Sonnets: Evidence of Dramatic Tension in the Interplay of Harsh and Gentle Sounds
}

\author{
Cynthia Whissell ${ }^{1}$ \\ ${ }^{1}$ Psychology Department, Laurentian University, Canada \\ Correspondence: Cynthia Whissell, Psychology Department, Laurentian University, Sudbury, Ontario, P3E 2C6, \\ Canada. E-mail: Cwhissell@Laurentian.ca
}

Received: September 4, 2017 Accepted: September 21, 2017 Online Published: November 2, 2017

doi:10.5539/ells.v7n4p1 URL: http://doi.org/10.5539/ells.v7n4p1

\begin{abstract}
This paper addresses the role of meaningful sounds in poetic communication. A sound symbolic system (Whissell, 2000) was employed to score Shakespeare's 154 sonnets in terms of the percentage of Harsh (e.g., sh, oo, r, k, p) and Gentle (e.g., l, long e, th, eh, m) sounds in each line. Significant differences in the employment of emotional sounds across lines suggest that the structure of the sonnets is affectively dramatic. Four stages unfold across three quatrains and a couplet. These are the establishment of the problem (lines 1-4; excess of Harsh sounds), its enlargement (lines 5-8; greater dominance of Harsh sounds), multiple emotional reversals (lines 9-12; alternating ascendance of Gentle and Harsh sounds), and a closing coda (lines 13, 14; an echo of the sounds in the first quatrain). In the order of their publication, which has been touted as potentially autobiographical, the sonnets provide a picture of repeated swings between Gentle and Harsh emotional extremes. Individual sonnets critically recognized for their distinctive emotional tone display the appropriate preponderance of Gentle or Harsh sounds.
\end{abstract}

Keywords: sound symbolism, emotion, Shakespeare, sonnets

\section{Introduction}

\subsection{Sounds in Shakespeare's Sonnets}

When Shakespeare's sonnets are read aloud, they can be heard to include many emotionally harsh sounds such as $\mathrm{sh}$, oo, and k (all found in the word "shook"), as well as many emotionally gentle ones such as 1, v, and long e (found in "lovely"). It is argued here that emotionally communicative sounds establish dramatic tension and characterize reversals of affect (voltas) within the sonnets. The emotional effects of sound structures in the sonnets need not have been achieved at a conscious level; Shakespeare was a consummate dramatist so it is not necessary to assume that he purposefully manipulated sounds when creating his poems.

Shakespeare's works have been studied assiduously for the past several centuries. They have been analyzed by those famous in their own right such as Samuel Johnson (Note 1) and Samuel Taylor Coleridge, (Note 2) as well as a plethora of others, and they continue to be analyzed today for several reasons. Some critics are passionately attached to the works themselves, while others are eager to apply new modes of understanding to materials of import. Vendler (1997) studied and wrote about Shakespeare's sonnets for the first of these reasons ("Why should I add another book to those already available? ... because I admire the sonnets," p. 1). Kohonen, Katajamäki, and Honkela (Note 3), on the other hand, applied neural networking models to the sonnets in order to demonstrate the "advantage of the self-organizing maps analysis" in the study of literary texts. The research in this article was conducted for both of the above reasons - an admiration of the sonnets and a desire to throw new light on them by applying a new method of analysis.

\subsection{Structure of the Sonnets and the Collection of Sonnets}

One hundred and fifty-four sonnets attributed to Shakespeare were published as a group in a 1609 quarto volume. A facsimile of the quarto sonnets is reprinted by Vendler (1997). Each sonnet contains 14 lines (there are two exceptions: sonnet 99 has 15 lines and sonnet 126 has only 12), and each is structured in a pattern of three quatrains followed by a couplet (Q1, Q2, Q3, and C). The sonnets were written in iambic pentameter, a 10-part meter of alternating unstressed and stressed syllables (for example, "Shall I compare thee to a summer's day," where the five stressed syllables are underlined). The rhyming structure for Shakespeare's sonnets is abab, cdcd, 
efef, gg: line 1 rhymes with line 3 , line 2 with line 4 , line 5 with line 7 , and so on. A sample sonnet (10) is reproduced in Table 1 where its quatrains, couplet, and rhyming pattern are identified.

Table 1. Sonnet 10 analyzed in terms of its structure and sound patterns

\begin{tabular}{|c|c|c|c|c|c|c|}
\hline Quatrain/Function & Line & Text & Rhyme & Tone & $\% \mathrm{H}$ & $\% \mathrm{G}^{*}$ \\
\hline Q1 & 1 & For shame! deny that thou bear'st love to any, & a & Gentle & 29 & 43 \\
\hline \multirow[t]{3}{*}{ Introduction to the problem } & 2 & Who for thy self art so unprovident. & $\mathrm{b}$ & Mixed & 30 & 30 \\
\hline & 3 & Grant, if thou wilt, thou art belov'd of many, & a & Gentle & 33 & 30 \\
\hline & 4 & But that thou none lov'st is most evident: & $\mathrm{b}$ & Mixed & 24 & 38 \\
\hline Q2 & 5 & For thou art so possess'd with murderous hate, & $\mathrm{c}$ & Harsh & 36 & 18 \\
\hline \multirow[t]{3}{*}{ Enlargement of the problem } & 6 & That 'gainst thy self thou stick'st not to conspire, & $\mathrm{d}$ & Harsh & 38 & 21 \\
\hline & 7 & Seeking that beauteous roof to ruinate & $\mathrm{c}$ & Harsh & 52 & 15 \\
\hline & 8 & Which to repair should be thy chief desire. & $\mathrm{d}$ & Harsh & 2 & 35 \\
\hline Q3 & 9 & O! change thy thought, that I may change my mind: & e & Gentle & 12 & 42 \\
\hline \multirow[t]{3}{*}{ Reversal and Resolution } & 10 & Shall hate be fairer lodg'd than gentle love? & $\mathrm{f}$ & Mixed & 28 & 34 \\
\hline & 11 & $\mathrm{Be}$, as thy presence is, gracious and kind, & e & Mixed & 32 & 32 \\
\hline & 12 & Or to thyself at least kind-hearted prove: & $\mathrm{f}$ & Harsh & 43 & 33 \\
\hline $\mathrm{C}$ & 13 & Make thee another self for love of me, & $\mathrm{g}$ & Gentle & 13 & 50 \\
\hline Reversal, Coda & 14 & That beauty still may live in thine or thee. & $\mathrm{g}$ & Gentle & 23 & 50 \\
\hline
\end{tabular}

Each sonnet operates as a packaged whole and unfolds its own plot; it presents, enlarges, and then resolves a problem which makes it dramatic rather than merely lyrical in form (Berkelman, 1948). Hunter (1953) suggests that Shakespeare's audience should forego the autobiographical approach to the sonnets (which looks for clues to the author's life story in their structure and content) in favor of the dramatic approach (which focuses on the author's attempt to create dramatic tension and resolve it within the sonnet form). Hunter's argument is partly based on the fact that Shakespeare was, first and foremost, a dramatist. When Dubrow (1981) argues forcibly against the dramatic nature of the sonnets, she is referring to the fact that they are not narratives and that they do not take place in real time. These arguments do not exclude the possibility that sonnets rely on dramatic tension for their effect. For Vendler (1997, p. 25), the sonnets represent "a mind working out positions" so that Q1 states a problem, Q2 enlarges upon it, and Q3 resolves it. Vendler stressed the fact that the resolution occurs in Q3, not $\mathrm{C}$, the coda, which summarizes the whole and sounds the closing note. Berkelman (1948) also observed that sonnets generally "turn" on line 9, and that the problem begins to be resolved there. Sonnet writing advice "For Dummies" ${ }^{\circledR}$ (Note 4) labels Q1 as an exposition, Q2 as an extension or complication, Q3 as a twist or reversal and $\mathrm{C}$ as a summary with a concluding image.

The model of sonnet as unfolding affective drama can be applied to sonnet 10 (Table 1). The person to whom Shakespeare addressed sonnet 10 is loved but not loving (Q1); in fact this person is filled with inappropriate hate (Q2); the person is encouraged to change for the better (Q3), and the couplet (C) brings the poet into the picture and finalizes the advice. The pattern of problem, enlargement, resolution, and coda is also evident in well-known sonnets such as number 130 ("My mistress' eyes are nothing like the sun") which opens with a description of an imperfect mistress (Q1), expands upon her imperfections (Q2), brings the mistress back to earth $(\mathrm{Q} 3)$, and closes with an expression of affection (C), and number 18 ("Shall I compare thee to a summer's day") which praises the loved one's beauty (Q1), and points out that beauty in nature tends to fade (Q2), but that even Death cannot cause the memory of the loved one to fade (Q3), because the poet sings its praises (C).

Many critics have questioned whether the order in which the sonnets were published could be attributed to Shakespeare himself, and whether the sonnets as a group tell an autobiographical story (e.g., Crosman, 1990; Hunter, 1953; Vendler, 1997, p. 14). From the viewpoint of reader response criticism, Risden (2017, p. 14) asserts that Shakespeare's sonnets, and especially those in the first two sections, create "veiled plots" which encourage the reader to "fill out the narrative with guesses" with reference to the author's biography. Kernot, Bossomaier, \& Bradbury (2017) employed linguistic analyses to successfully differentiate the Procreation sonnets (1-17) from the Rival Poet sonnets (78-86) and the Dark Lady sonnets (127-154), again pointing to a meaningful organization of sonnets within the collection. Even if the sonnets do not tell the story of the author's life, the collection is seen as being structured rather than random. For example, Vendler describes sonnets 40 through 42 as "betrayal sonnets" (1997, p. 217) and draws parallels between them and sonnets 133 through 136. Comments such as these suggest that sonnets of a similar mood are found in close proximity to one another in 
emotional neighbourhoods.

\subsection{Quantifying the Employment of Emotionally Loaded Sounds in Sonnets}

When people say words such as "shook" and "lovely" out loud, they employ a series of phonemes or word sounds. Sounds are not identical to letters, but are systematically related to them by a language's rules of pronunciation (for example, the sh in "shook" is two letters but one sound, and the y at the end of "lovely" is pronounced as a long e). Several 20th century analysts focused on the importance of the natural meaning communicated by word sounds (e.g., Jakobson \& Waugh, 2002). Poets who wrote critically about poetry (e.g., Alexander Pope (Note 5) and Edgar Allan Poe (Note 6), discussed in Whissell, 2004, 2011b) also addressed the importance of sound in the communication of poetic meaning. Sound symbolists have described the possible meaning of sounds (e.g., 1 as sweet, $r$ as tough) and sound combinations (e.g., gl as glittery, tz as sharp), but they provided no comprehensive system for the quantification of sound meanings.

In her research on affective sound symbolism, Whissell $(1999,2000)$ examined English word sounds inductively and reached the conclusion that most of them were emotionally meaningful. She analyzed the sounds in several thousand words whose emotional meaning had been rated, and noted that different sounds appeared at inordinately high rates in different types of rated words. Sh, oo, and k, for example, appeared in many different kinds of words but they appeared at higher rates in words rated by volunteers as both unpleasant and active. L, v, and long e, on the other hand appeared at higher rates in words rated by volunteers as both pleasant and passive. Word sounds were associated with other combinations of perceived pleasantness and activation, but this research focuses on pleasant/passive or Gentle and unpleasant/active or Harsh sounds. In total, 10 word sounds occurred more frequently in gentle words such as lovely, bluebell, calm, leisure, and myth. These were 1, v, long e (the vowel in "lee"), soft e (the vowel in "set"), soft a (the vowel in "lawn"), ai (the diphthong vowel in "mind"), soft th (the th in "thumb"), hard th (the th in "that"), $m$, and $z$, which were inductively labelled as Gentle sounds. The IPA symbols for these sounds, in order of mention, are $1, \mathrm{v}, \mathrm{i}, \varepsilon\lrcorner$, ar, $\theta, \delta, \mathrm{m}$, and $\mathrm{z}$. Twelve sounds appeared more often in harsh words such as shook, murder, tramp, gnaw, and dying. These were sh, oo (the vowel in "fool"), k, er (the ending of "her"), r, d, g, t, p, ng (appearing in any "-ing" ending), short e (the vowel in "bit"), and oi (the diphthong vowel in "boy"), which were inductively labelled as Harsh sounds. The IPA symbols for these sounds, in order of mention, are $\int, \mathrm{u}, \mathrm{k}, 3 \mathrm{r}, \mathrm{r}, \mathrm{d}, \mathrm{t}, \mathrm{p}, \mathrm{y}, \mathrm{I}$, and I.

Although Whissell's quantification of sound emotionality was a statistical one that rested entirely on the tendency of sounds to appear more often in certain types of emotional words, a post hoc analysis led to the conclusion that sounds in different emotional categories are also enunciated differently-they involve different facial and muscle actions (Whissell, 2000). For example, pronouncing the sh and oo of shook produces something of an angry facial expression while pronouncing the long e of at the end of lovely produces a smile (just as the long e in "cheese" does). As well, when people say "shook" they create a series of relatively rigid mouth postures, while when they say "lovely" mouth postures are looser and more liquid. The category of Harsh sounds includes $r$, which requires a rigid tongue posture, and many plosive consonants $(t, d, p, k, g$-so named because of the minor explosion of breath involved in their enunciation), while the category of Gentle sounds includes many vowels (ay, long e, soft e, ai, and soft a) but no plosive consonant. Line 1 of sonnet 40 ("Take all my loves, my love, yea take them all") contains an extreme proportion of Gentle sounds, while line 11 of sonnet 112 ("To critic and to flatterer stopped are") contains an extreme proportion of Harsh ones. A person reciting these lines out loud will notice how different they feel-physically-from one another, and what a different sound pattern they produce as well. Even though it contains $\mathrm{t}$ and $\mathrm{k}$, sounds classified as Harsh, the first line flows off the tongue and contains many repetitions of the liquid sound 1 . The second line tends to trip the tongue: it contains many plosive sounds such as $\mathrm{t}, \mathrm{k}$, and $\mathrm{p}$, and it is spoken in a more staccato fashion. Method of articulation is related to the characteristics of the sound produced, and both method and sound signal vary systematically across categories of emotional words.

The approach to the sonnets through their meaningful sounds involves a study of iconicity ("a natural or logical connection between the form and meaning of signs," Toolan, 2017, p. 61) where sounds are considered iconic of the emotion in the poetry, and the relationship between sound and meaning is a natural one based on facial expression and the chacteristics of sound signals.

\subsection{Research Questions}

In this research, all 154 sonnets were phonetically transcribed (i.e., rendered into their basic sound patterns), and examined line by line in terms of their employment of Harsh and Gentle sounds in order to answer three research questions. The two types of emotionally communicative sounds are appropriate choices for poems that deal largely with gentle themes such as love and longing and harsh ones such as rebuff and rejection. To address the 
first research question of differences among sonnets in terms of their sound emotionality, sonnets are compared to one another and the harshest- and gentlest-sounding among them are identified. Critics' evaluations of individual sonnets are aligned with the results of this analysis. The second question of the research addresses the location of the volta or emotional reversal within the sonnets; this was expected to occur between lines 8 and 9 (at the beginning of Q3), with an echo possibly appearing between lines 12 and 13 (between Q3 and the beginning of the concluding couplet). A reversal (cross-over) in the relative employment of Harsh and Gentle sounds is accepted as evidence of a volta. The third question of the research examines the potential presence (and, thereafter, meaningfulness) of emotional fluctuations within the ordered collection of sonnets. Scores for the full set of 154 sonnets are examined in a search for an over-arching emotional structure to the collection.

\section{Method}

\subsection{Materials and Scoring for Emotional Sounds}

The text of the sonnets in the World Library version was downloaded from Project Gutenberg (etext \#1041) in June of 2011. The sonnets were phonetically transcribed by a computer program that had been prepared for the US Navy but is now in the public domain. The program is available at various locations on the web (Note 7). The resulting transcription was broad (i.e., lacking in subtlety), but it allowed for the identification of Harsh and Gentle sounds. For example, these are the opening lines of sonnet 4:

Unthrifty loveliness, why dost thou spend

Upon thy self thy beauty's legacy?

These lines were rendered, after the removal of punctuation marks, as:

\section{AHnTHrIHftIY lAHvEHIIHnEHs WHAY dOWst THAW spEHnd \\ AXpAOn THAY sEHIf THAY bIYAHTIHs IEHgAEsIY}

In this transcription, lower case letters such as $\mathrm{n}$ or $\mathrm{s}$ represent their own sounds, while upper case letter pairs such as TH and AY represent complex consonants and vowels. AX represents a neutral schwa (the vowel in the word "the"), and IY and IH represent long and short e sounds respectively. A more detailed description of the transcription system can be found in Whissell (2000). Harsh sounds from the above example include t, d, and $p$ while Gentle ones include IY, 1 , and TH.

A computer program written by the author counted the number of sounds in each line, and then computed the percentage of Harsh and Gentle sounds with respect to this total. Line 1 of sonnet 4 contains a total of 30 sounds: $10 / 30$ or $33 \%$ are Gentle sounds, $8 / 30$ or $27 \%$ are Harsh, and $12 / 30$ or $40 \%$ do not belong to either category Table 1 reports the proportion of Harsh and Gentle sounds for each line of sonnet 10. Similar computations were made for each line of every sonnet, and for each sonnet as a whole. To equalize length for the two irregular sonnets, two blank lines were added to sonnet 126 and lines were compacted for sonnet 99 .

\subsection{Two Measurement Issues and Their Resolution}

One problem attending any study of Shakespeare's sound patterns is original pronunciation. All languages change over time, and more than 400 years have elapsed since the publication of the sonnets. In a book celebrating the production of Romeo and Juliet in original pronunciation at the reconstructed Globe Theatre, Crystal (2005, pp. 63-115) explained how original pronunciation was recreated with the help of rhyme patterns and other clues. Crystal concluded that Shakespeare's English sounded no more different from today's Standard English than several current dialects of the language do (e.g., Scotts English). This conclusion was supported by the fact that although most audience members noticed the changed accent, they still understood the original pronunciation play. A sample of original pronunciation Shakespeare is available on YouTube in an excerpt from a University of Kansas production of Midsummer Night's Dream (Note 8).

Some of the Harsh and Gentle sounds counted in this study may have changed somewhat in their pronunciation over time. Crystal notes that this is true especially for $r$ and for some vowels, including the ea in "meat." Faced by ample evidence of change, a researcher might be tempted to ignore the original author's role in the sonnets and claim that the analyses in this article address only the modern reception of the sonnets (the sonnets as we hear them, not as Shakespeare would have heard them). However, while the pronunciation of $r$ has changed (it used to be pronounced like the $\mathrm{r}$ in "brrr," but is now pronounced more like the $\mathrm{r}$ in "bra"), and while the same is true for some vowels ("meet" and "meat" were originally pronounced as "meet" and "mate," but are now both pronounced as "meet"), the changes noted are a matter of degree. As well, there was minimal change in the pronunciation of several of the sounds analyzed here, notably the plosive consonants which dominate the Harsh category and 1 and $\mathrm{m}$, very frequent letters that play a strong role in the Gentle category. Newer pronunciations 
are variants of older ones, not opposites. Audiences' relatively effortless understanding of original pronunciation productions suggests that there is some easily accessed transformational relationship between Shakespeare's pronunciation and our own, so that conclusions based on a modern phonetic transcription might be cautiously generalized to the original Shakespearean pronunciation. As well, Toolan $(2017$, p. 57) points to the importance of integrational semiology in the interpretation of texts; this approach to meaning focuses on the "now" of interpretation and involves the assumption that any interpretation of a text is tied to one particular "now," and is not guaranteed to generalize to other instances of interpretation. From this perspective, one can only study a text in the "now" in which they approach it, regardless of when it was written.

The second background problem involves words. The emotional meanings of sounds were originally assigned on the basis of word meanings (Whissell, 1999, 2000). Differences among sonnet lines with respect to sounds might therefore be dependent entirely on Shakespeare's word choices. Oneway analyses of variance were conducted to examine this possibility. The between-groups variable was sonnet line, the cases were words, and the variables examined were word Harshness (unpleasantness and activation) and word Gentleness (pleasantness and passivity) as measured by the Dictionary of Affect in Language (Whissell, 2009). In spite of the statistical power associated with 14,992 observations, there were no significant differences among lines ( $p=.84$ for word Harshness and $p=.52$ for word Gentleness). The sound-based differences discussed in the following section were therefore not the inescapable outcome of word choices; they depend, instead, on the individual sounds produced when words are enunciated.

\section{Results}

\subsection{General Emotionality of the Sonnets and Differences among Sonnets}

The sonnets contain a total of 59,510 sounds, or 386 per sonnet and 28 per line. The percentage of Harsh sounds in each sonnet ranged from 24 to 41 , with a mean of 32.8 and a standard deviation of 3 . The percentage of Gentle sounds ranged from 21 to 42 with a mean of 30.8 and a standard deviation of 3.5. The existence of a large proportion of independent sounds (36\% of all sounds are neither Harsh nor Gentle) suggests that the frequencies of Harsh and Gentle sounds are not strictly dependent on one another: they are free to both rise and fall together, or to move in opposite directions. Given the standard deviations reported above, it is mathematically possible for a line to contain both the maximum number of Harsh sounds (41\%) and the maximum number of Gentle ones (42\%). However, as the two sets of sounds convey emotionally opposite information, it is more likely that the percentage of one type would be maximized where the other was minimized.

The percentages of Harsh and Gentle sounds in the sonnets were compared to those in a normative group of the 100 most frequently anthologized English poems (from Harmon, 1992) with a $z$ test comparing a sample to a population proportion. The poems in the comparative set were those most frequently encountered in collections or anthologies, and could therefore be considered "best-known" poems. The percentage of Harsh sounds in the sonnets did not differ from that in the familiar poems $(z=1.46, p>.05)$, but Shakespeare's sonnets included more Gentle sounds than the familiar norm (30.8 versus $29.5, z=6.61, p<.01)$. To the ear broadly familiar with English poetry, the sonnets would sound relatively gentle. The framing of Harshness and Gentleness as opposite emotions was confirmed by the fact that sonnets employing more Harsh sounds tended to employ fewer Gentle ones and vice versa $\left(r_{152}=-.61,95 \% ; \mathrm{C}:-.50,-.70\right)$.

Sonnets of strikingly Gentle sound-tone were numbers 40 ("Take all my loves, my love, yea take them all"), 42 ("That thou hast her it is not all my grief"), and 136 ("If thy soul check thee that I come so near"). The relatively Harshest sonnets were numbers 58 ("That God forbid, that made me first your slave"), 84 ("Who is it that say most, which can say more"), and 129 ("The expense of spirit in a waste of shame"). The contents of these sonnets and critics' readings of them validate the classification based on sound percentages. According to Vendler, sonnet 40 displays "abjectness in love" (1997, p. 107) and its words suggest that the speaker is willing to love, even when the beloved is unfaithful ("I cannot blame thee, for my love thou usest"-line 6). Addressing a similar theme of betrayal by the still-beloved, sonnet \#42 bewails "A loss in love that touches me more nearly" (line 4) and sonnet \#136 pleads (with some degree of humor) "Make but my name thy love, and love that still," (line 13). In contrast to the pathos and submissive playfulness of the gentler sonnets, the harsher ones display negative emotions such as jealousy and aggravation. Sonnet 58 is a "sardonic fantasia" (Vendler, 1997, p. 277) in which the speaker is a "slave" who struggles in the grip of love, while sonnet 84 is accusatory and taxes the beloved with having too great a fondness for praise (from other poets). Sonnet 129 is the "lust" sonnet where lust is described as "Perjur'd, murderous, bloody, full of blame," (line 3) and only fleetingly pleasurable- -Enjoy'd no sooner but despised straight" (line 5). 


\subsection{Differences in Emotionality among Sonnet Lines}

A multivariate analysis of variance was performed for the percentage of Harsh and Gentle sounds with line and sonnet as factors. Each single sonnet line $(N=2154)$ was a case, and the interaction of the two factors served as the error term. The multivariate tests for line and sonnet both led to a rejection of the null hypothesis of no difference $\left(\mathrm{F}_{26,3974}=3.31, p<.001, \eta=.15 ; \mathrm{F}_{306,3974}=2.06, p<.001, \eta=.37\right.$ for Harsh and Gentle sounds respectively). Univariate tests indicated that there were significant differences among both lines $\left(\mathrm{F}_{13,1987}=5.27, p<.001, \eta=.18\right.$; $\left.\mathrm{F}_{13,1987}=3.69, p<.001, \eta=.15\right)$ and sonnets $\left(\mathrm{F}_{153,1987}=2.02, p<.001, \eta=.37 ; \mathrm{F}_{153,1987}=2.42, p<.001, \eta=.40\right)$ for both Harsh and Gentle sounds.

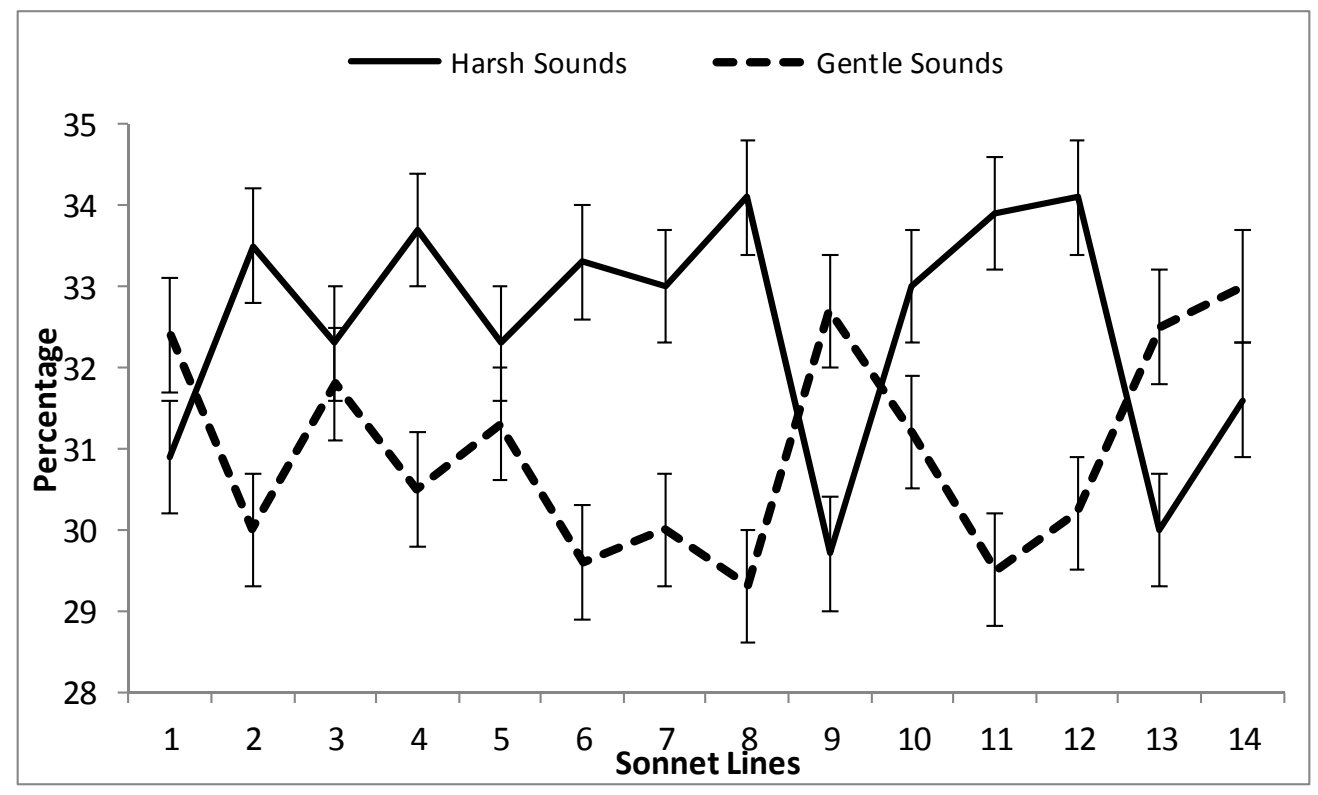

Figure 1. Percentage of Harsh and Gentle sounds in each line

Note. Lines 1-4 represent the first quatrain, lines 5-8 the second, lines 9-12 the third and lines 13 and 14 the coda. Whiskers at each point denote the standard error of the mean. Non-overlapping whiskers indicate the presence of significant differences.

The percentage of Harsh and Gentle sounds in each of the 14 sonnet lines is depicted in Figure 1. Harsh sounds are represented by a solid line and Gentle sounds by a broken one; standard error bars are provided at each data point. The results of post hoc t-tests indicated that the use of Harsh and Gentle sounds was different for many lines $(p<.05)$. The exceptions were lines 1, 3, 5, 10, and 14. The unfolding dramatic tension in the sonnets is evident in the sound patterns of Figure 1. The sonnets introduce a problem most notably in lines 2 and 4 where Harsh sounds predominate: Q1 is the establishment quatrain. Sound patterns demonstrate an enlargement of this problem in lines 6, 7, and 8 where the difference between Harsh and Gentle sounds opens up in favor of Harsh sounds: Q2 is the enlargement quatrain. The first volta, indicated by the crossing of lines representing Harsh and Gentle sounds, occurs between lines 8 and 9 . A second volta occurs between lines 9 and 10, and a third between lines 12 and 13: Q3 is defined by the turbulence of its emotional reversals. C, the couplet, serves as a coda to the sonnets and the closing line has the same emotional tone as the first line.

There is a second pattern evident in Figure 1-a pattern which differentiates odd-numbered lines from even-numbered ones. The first set of lines $(1,3,5,7,9,11$, and 13) includes fewer Harsh and more Gentle sounds than the second $(2,4,6,8,10,12$, and 14). The difference in proportions is significant for both types of sounds (.317 versus .333 for Harsh sounds and .315 versus .305 for Gentle ones, $z>3, p<.001$ ). If drum beats served as a metaphor for this difference, the stronger (Harsh) beat would be the second one for each pair of lines. 


\subsection{Fluctuations in Emotion across the Collection of Sonnets: A Descriptive Analysis}

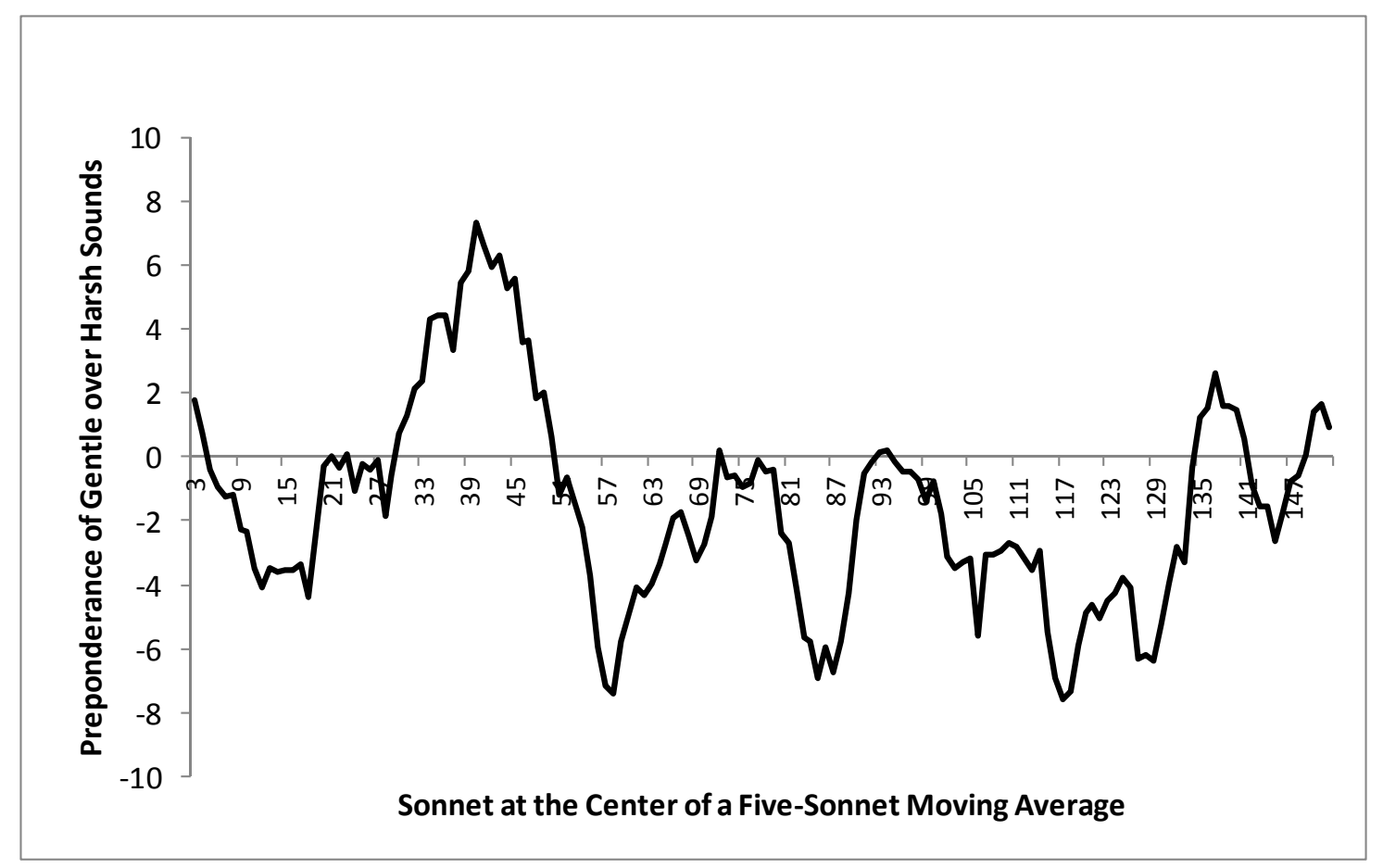

Figure 2. Emotional variations across the entire collection plotted in terms of a five-sonnet moving average

Note. The zero line of the graph represents an equal proportion of Harsh and Gentle sounds. Positive numbers indicate the percent excess of Gentle over Harsh sounds and negative numbers the percent excess of Harsh over Gentle ones.

The sonnets were emotionally variable and it was difficult to visually identify time-ordered patterns for the use of Harsh and Gentle sounds separately in the entire collection. This difficulty was addressed by two techniques that streamlined the data. Rather than being described by one score for the use of Harsh sounds and another for the use of Gentle sounds, each sonnet received a single score computed as a difference between the percentage of Gentle and Harsh sounds. A smoothing technique known as a moving average was then applied to difference scores: the score for each sonnet was averaged with those for the two which came before and the two which came after it. This smoothing technique de-emphasizes individual sonnet-to-sonnet differences and instead treats sonnets as if they exist in emotional neighborhoods, where several successive sonnets express roughly similar emotions. (Note 9) Moving averages highlight structures that are present, but they can never create structure out of chaos. If emotions fluctuated randomly across the collection, the result of applying a moving average would be a flat line, not the distinctively shaped line in Figure 2. The employment of moving averages in forecasting is discussed by Hyndman and Athanasopoulos (2014, Section 6/2). This research includes an attempt to forecast predominant emotion from time, which is represented by the sequence of sonnets. The analysis in this section of the paper is largely descriptive rather than statistical, but the last paragraph of the section provides some statistical validation for the curve in Figure 2.

There is an emotional structure to the collection when sonnets are ordered as they were in the 1609 quarto. When the line in Figure 2 rises it depicts sonnets with predominantly Gentle sounds, and, when it falls, sonnets with predominantly Harsh ones. The first 18 sonnets, sometimes called the procreation sonnets because they advise a young man to marry and have offspring, show a moderately decreasing Gentleness across sonnets. There follow a series of increasingly Gentle sonnets which culminate in the peak near sonnet 40 , which is among the Gentlest of the collection. Sound emotions turn after this sonnet and its neighbors and begin to fall abruptly reaching a trough of Harshness in the neighborhood of sonnet 58 ("Being your vassal bound to stay your leisure"-line 4). The pattern of increasing Gentleness in sounds followed by increasing Harshness occurs two further times within the 126 "fair young man" sonnets, with peaks of Gentleness in the neighborhood of sonnets 73 ("Bare ruined choirs, where late the sweet birds sang"-line 4) and 93 ("Thy looks with me, thy heart in other place"-line 4) and troughs of Harshness in the neighborhood of sonnets 84 ("You to your beauteous blessings add a curse" -line 13) and 117 ("Accuse me thus, that I have scanted all"-line 1). The "dark lady" sonnets, which being at 
127, include a Harsh trough in the neighborhood of 129, the lust sonnet ("Savage, extreme, rude, cruel, not to trust"-line 4), and a Gentle peak around sonnet 136 ("Thus far for love, my love-suit, sweet, fulfil"-line 4). In this collection, Gentle sounds seem to be associated with submission as well as whimsy and more obviously positive emotions.

Figure 2 suggests a possible interpretation for the collection of sonnets. If the sonnets were printed in the same order in which they were written, and if they are autobiographical (two very big ifs), the poet must have experienced several cycles of alternating Gentleness (submission, affection, hope) and Harshness (anger, criticism, rejection), though it is notable that he never again matched the Gentleness expressed in the neighborhood of sonnet 40, where the curve in Figure 2 reaches its highest and therefore gentlest point. There are widely recognized sub-groups among the sonnets, such as the Procreation sonnets (1-17), the Rival Poet sonnets (78-86) and the Dark Lady sonnets (127-154). Kernot, Bossomaier, \& Bradbury (2017) have statistically confirmed the presence of textual consistencies that validate these subgroups. Data from Figure 2 add to our understanding of the sonnets by illustrating the presence meaningful emotional differences within each of the identified groups: for example, there is a distinct drop in sound gentleness across the Procreation sonnets, and an equally clear rise in gentleness within the earlier Dark Lady sonnets. There is also a V-shape in the curve for the Rival Poet sonnets with sound gentleness first falling and then rising. An emotional plot structure underlies each of the various subgroups.

For readers interested in a statistical treatment, the moving average depicted in Figure 2 was successfully $(R=.70$, $p<.0001$ ) predicted in a forced entry polynomial regression with sonnet number and the second through tenth powers of number as predictors. In the standardized formula, the predicted moving average was equal to $-.26 *$ order $+2.12 *$ order $^{2}=3.12 *$ order $^{3}-5.12 *$ order $^{4}+1.09 *$ order $^{5}+12.45^{*}$ order $^{7}-9.35^{*}$ order $^{9}-.18^{*}$ order $^{10}$. Issues with collinearity led to the exclusion of $\operatorname{order}^{8}$. The predicted moving average duplicates the early drop in relative gentleness (within the first 20 sonnets), the rise in relative gentleness to a peak around sonnet 40 , a further (non-linear) drop to extreme harshness in the region of sonnet 126, and a final rise in gentleness in the area of sonnet 140 .

\section{Discussion and Conclusions}

This research and other similar efforts (e.g., Whissell, 2011a, b) emphasize the importance of perceptual-motor processes in poetic communication. Although words convey a great deal of the abstract and symbolic meaning in a language, the sounds of which they are composed contribute to this meaning, perhaps at an unconscious level, by the very nature of the motor skills employed in pronouncing them and the auditory characteristics of the sounds produced. Poetry is an oral/aural art and the meter, rhyme, assonance, alliteration in Shakespeare's sonnets confirm that the sonnets were meant to be spoken aloud and heard. With oral delivery and aural reception, both the speaker and the hearer would be subjected to the multitude of emotional messages embedded in the poems' sounds. Even many years after the sonnets were created, and in spite some of changes in the pronunciation of English, those reading or hearing the sonnets would receive the same emotional messages by association - sounds, muscle movements, and emotions would combine to convey meaning.

This analysis of the interplay of Harsh and Gentle sounds in Shakespeare's sonnets leads to five main conclusions. First, in comparison to poetry in general, the sonnets sound relatively gentle. Second, individual sonnets have a defining tone: some sonnets are considerably harsher-sounding than others, and some considerably gentler-sounding. Third, critics' interpretations of the emotions expressed in the sonnets are in agreement with interpretations based on the poems' sound patterns. Fourth, the sonnets have a dramatic emotional sound structure: the first quatrain establishes the problem, the second enlarges it, the third encompasses turbulent reversals of emotion and the final couplet provides the closing coda. Finally, there is an over-arching structure to the collection of sonnets indicating a repeated rise and fall of gentleness and harshness in their sounds which might parallel a succession of positive and negative experiences in the poet's life.

\section{References}

Berkelman, R. (1948). The drama in Shakespeare's sonnets. College English, 10, 138-141. https://doi.org/10.2307/371802

Crosman, R. (1990). Making love out of nothing at all: the issue of story in Shakespeare's procreation sonnets. Shakespeare Quarterly, 41(4), 470-488.

https://doi.org/10.2307/2870777

Crystal, D. (2005). Pronouncing Shakespeare: The Globe experiment. Cambridge, UK: Cambridge University Press. https://doi.org/10.1017/CBO9780511487019 
Dubrow, H. (1981). Shakespeare's undramatic monologues: towards a reading of the sonnets. Shakespeare Quarterly, 32, 55-68. https://doi.org/10.2307/2870286

Harmon, W. (1992). The top 500 poems. NY: Columbia University Press.

Hunter, G. K. (1953). The dramatic technique of Shakespeare's sonnets. Essays in Criticism, III(2), 152-164. https://doi.org/10.1093/eic/III.2.152

Hyndman, R. J., \& Athanosopoulos, G. (2012). Forecasting: Principles and practice. Section 6/2. Retrieved from https://www.otexts.org/fpp

Jakobson, R., \& Waugh, L. R. (2002). The Sound Shape of Language (3rd edition). Berlin: Mouton de Gruyter. https://doi.org/10.1515/9783110889451

Kernot, D., Bossmaier, T., \& Bradbury, R. (2017). Novel text analysis for investigating personality: identifying the dark lady in Shakespeare's sonnets. Journal of Quantitative Linguistics. https://doi.org/10.1080/09296174.2017.1304049

Risden, E. L. (2017). On Shakespeare in sonnets: A study in the theory and practice of reader response criticism. Newcastle upon Tyne UK: Cambridge Scholars Publishing.

Toolan, M. (2017). Stylistic iconicity and Love's two orders of language. Language Sciences, 61, 56-63. https://doi.org/10.1016/j.langsci.2016.09.016

Vendler, H. (1997). The art of Shakespeare's sonnets. Cambridge, MA: The Belknap Press of Harvard University Press.

Whissell, C. (1999). Phonosymbolism and the emotional nature of sounds: evidence of preferential use of particular phonemes in text of differing emotional tone. Perceptual and Motor Skills, 89, 19-48. https://doi.org/10.2466/pms.1999.89.1.19

Whissell, C. (2000). Phonoemotional profiling: a description of the emotional flavor of English texts on the basis of the phonemes employed in them. Perceptual and Motor Skills, 91, 617-648. https://doi.org/10.2466/pms.2000.91.2.617

Whissell, C. (2004). "The sound must seem an echo to the sense": Pope's use of sound to convey meaning in his translation of Homer's Iliad. Perceptual and Motor Skills, 98, 859-864. https://doi.org/10.2466/pms.98.3.859-864

Whissell, C. (2009). Using the revised Dictionary of Affect in Language to quantify the emotional undertones of samples of natural language. Psychological Reports, 105, 509-521. https://doi.org/10.2466/PR0.105.2.509-521

Whissell, C. (2011a). Sound and emotion in Milton's Paradise Lost. Perceptual and Motor Skills, 113, 257-267. https://doi.org/10.2466/04.21.28.PMS.113.4.257-267

Whissell, C. (2011b). "To those who feel rather than to those who think": sound and emotion in Poe's poetry. Journal of English and Literature, 2, 149-156. Retrieved from http://www.academicjournals.org/article/article1379424964_Whissell.pdf

\section{Notes}

Note 1. http://ebooks.adelaide.edu.au/j/johnson/samuel/preface/

Note 2. http://openlibrary.org/books/OL23289155M/Coleridge's_essays_lectures_on_Shakespeare

Note 3. http://research.ics.tkk.fi/events/AKRR05/papers/amklc05kohonen.pdf

Note 4. Dummies, a Wiley brand, at http://www.dummies.com/how-to/content/writing-a-sonnet.html

Note 5. In Pope's Essay on Criticism, available at: http://poetry.eserver.org/essay-on-criticism.html

Note 6. In Poe's Philosophy of Composition. Retrieved from http://xroads.virginia.edu/ HYPER/poe/composition.html

Note 7. e.g., at http://www.cs.cmu.edu/afs/cs/project/ai-repository/ai/areas/speech/systems/eng2phon/0.html

Note 8 . http://www.youtube.com/watch? $=\mathrm{dWe} 1 \mathrm{~b} 9 \mathrm{mjjkM} \&$ feature=relmfu

Note 9. https://robjhyndman.com/papers/movingaverage.pdf 


\section{Copyrights}

Copyright for this article is retained by the author, with first publication rights granted to the journal.

This is an open-access article distributed under the terms and conditions of the Creative Commons Attribution license (http://creativecommons.org/licenses/by/4.0/). 